\title{
Surgical treatment of drug-resistant epilepsy caused by gliomas in eloquent areas: experience report
}

\author{
Tratamento cirúrgico de epilepsias refratárias causadas por gliomas localizados em áreas \\ eloquentes: uma série de casos brasileiros \\ Gustavo Rassier ISOLAN 1,2, Vilson MARTH1,2, Leonardo FRIZON1,2, Leandro DINI1,2, Simone DINI,2, Vitor Nagai \\ YAMAKI ${ }^{3}$, Eberval Gadelha FIGUEIREDO3
}

\begin{abstract}
Drug-resistant epilepsy associated with central nervous system tumors is generally caused by low grade gliomas. This group of tumors is usually found in brain eloquent areas, such as the insular lobe, rolandic cortex and supplementary motor area and, historically, possess a greater risk of postoperative deficits. Objective: The aim of this investigation was to present our surgical experience on patients with drug-resistant epilepsy caused by gliomas in eloquent areas. We retrospectively investigated variables that impact seizure control, such as tumor location, extent of resection, invasion into the lenticulostriate arteries in the patient, especially those with insular gliomas. Methods: Out of 67 patients with eloquent area brain tumors operated on in our service between 2007 and 2016, 14 patients had symptoms of drug-resistant epilepsy. Volumetric analysis, extent of resection (EOR), type of approach and mapping, among other factors were correlated with the 12-month postoperative seizure outcome. Results: Univariate analysis showed that the factors showing statistical relevance with seizure control were preoperative volume $(p=0.005)$, EOR $(p=0.028)$ and postoperative volume $(p=0.030)$. Conclusion: There was a statistically significant association between the EOR and the Engel score for epilepsy control: an EOR < 70 was associated with Engel II, III, IV and an EOR > 90 was associated with Engel I. Eloquent area gliomas can safely be resected when surgeons use not only microsurgical anatomy concepts but also brain mapping.
\end{abstract}

Keywords: Drug resistant epilepsy; brain neoplasms; brain mapping; glioma.

\section{RESUMO}

Epilepsia refratária secundária a tumores cerebrais são geralmente causadas por gliomas de baixo grau. Esse grupo de tumor é frequentemente localizado em áreas eloquentes do cérebro como na insula, córtex rolândico e área motora suplementar; e sua ressecção apresenta alto risco de déficits neurológicos no pós operatório. Objetivo: O objetivo do estudo consiste em apresentar nossa experiência no tratamento cirúrgico de pacientes com epilepsia refratária secundário a gliomas em áreas eloquentes. Métodos: 0 estudo consiste em investigação retrospectiva de variáveis que interferem no controle de crises, tais como localização do tumor, grau de ressecção, invasão tumoral de artérias lenticulo estriadas, principalmente em gliomas insulares. Dentre 67 pacientes portadores de gliomas em área eloquente operados no período de 2007 a 2016, 14 doentes apresentavam epilepsia refrataria associada. Análise volumétrica do tumor, grau de ressecção, acesso cirúrgico, bem como o uso de mapeamento cortical intraoperatório foram correlacionados com desfecho de controle de crises epilepticas em 12 meses. Resultados: Em análise univariada os fatores relacionados com controle de crises em 12 meses foram volume tumoral pré operatório ( $p=0,005)$, grau de ressecção ( $p=0,028)$ e volume tumoral pós operatório. Conclusão: 0 grau de ressecção apresentou significância estatística em relação ao controle de crises conforme escala de Engel. Ressecções menores que 70\% apresentaram correlação com Engel II, III e IV; enquanto ressecções maiores que 90\% apresentaram correção positiva com Engel I. Gliomas em áreas eloquentes podem ser ressecados de forma segura desde que seja realizada por equipe experiente com conhecimento acurado da anatomia microcirúrgica e emprego de mapeamento cortical intraoperatório.

Palavras-chave: Epilepsia refratária; neoplasias encefálicas; mapeamento encefálico; glioma.

${ }^{1}$ Centro Avançado de Neurologia e Neurocirurgia (CEANNE), Porto Alegre RS, Brasil;

${ }^{2}$ Hospital Moinho dos Ventos de Porto Alegre, Departamento de Neurologia e Neurocirurgia, Porto Alegre RS, Brasil:

3Universidade de São Paulo, Departamento de Neurocirurgia, São Paulo SP, Brasil.

Gustavo Rassier Isolan (iD) https://orcid.org/0000-0002-7863-0112; Vilson Marth (iD) https://orcid.org/0000-0003-0814-0449; Leonardo Frizon (iD) https://orcid.org/0000-0001-8304-3425; Leandro Dini（iD https://orcid.org/0000-0002-8463-1437; Simone Dini iD https://orcid.org/0000-0001-8967-1860; Vitor Nagai Yamaki (iD https://orcid.org/0000-0003-4872-1731; Eberval Gadelha Figueiredo iD https://orcid.org/0000-0001-7754-4178

Correspondence: Gustavo Rassier Isolan; Rua Dr Eneas de Carvalho Aguiar, 255; 05402-000 São Paulo SP, Brasil; E-mail: gisolan@yahoo.com.br Conflict of interest: There is no conflict of interest to declare.

Received 25 December 2018; Received in final form 06 June 2019; Accepted 06 August 2019. 
The International League Against Epilepsy (ILAE) defines drug-resistant epilepsy as "failure of adequate trials of two tolerated and appropriately chosen anti-epileptic drug schedules (whether as monotherapy or in combination) to achieve seizure freedom" ${ }^{1}$. Drug-resistant epilepsy may result in cognitive impairment, diminished quality of life, and even neuropsychological damage or death ${ }^{2,3}$.

Drug-resistant epilepsy secondary to central nervous system tumors is generally caused by low grade gliomas $4,5,6,7,8,9$. This group of tumors is usually found in brain eloquent areas, such as the insular lobe, rolandic cortex and supplementary motor area ${ }^{6}$. Performing surgery on patients with this condition has potential not only to treat drug-resistant epilepsy ${ }^{7,10}$ but also to improve overall survival $^{7,11,12,13,14}$. However, operating on tumors in the so-called eloquent areas carries a significant risk of postoperative deficits. Refined surgical techniques, based on microneurosurgical anatomy ${ }^{15,16,17}$ and brain mapping, have permitted safe resection with minimal risk ${ }^{18,19,20,21,22}$.

In the present study, we reviewed our surgical experience in resection of low-grade gliomas in eloquent areas causing drug-resistant epilepsy, and determined the most relevant variables related to seizure control.

\section{METHODS}

\section{Patient population}

The study was approved by the Institutional Review Board of the Federal University of Rio Grande do Sul. All patients provided written informed consent.

From 67 eloquent area brain tumors operated on between 2007 and 2016, 14 patients had symptoms of drug-resistant epilepsy. The cases were individually analyzed according to the tumor's location; while insular gliomas were classified based on the Yaşargil ${ }^{23}$ and Berger-Sanai ${ }^{12}$ criteria. The histological tumor type was defined according to the 2016 World Health Organization classification ${ }^{24}$. Handedness and language dominance were determined using the Portuguese Edinburgh Handedness Inventory ${ }^{25}$.

Several eloquent cortical and subcortical regions have been identified in brain mapping studies. We focused on tumors within or adjacent to those eloquent areas, such as the rolandic cortex, supplementary motor area, corona radiata, internal capsule, uncinate fasciculus, dominant temporal, dominant mid-to-posterior frontal, and dominant midto-anterior parietal lobes ${ }^{26}$.

For functional outcomes assessment, we applied the following preoperative tests: the Picture Naming Test and the Boston Diagnostic Aphasia Examination ${ }^{27}$, as well as the Karnofsky Performance Status scale ${ }^{28}$. The clinical outcome in the immediate and six-month postoperative period was categorized as "normal", "motor deficit" or "speech disorder".
To evaluate seizure control in the follow-up, we used the Engel outcome scale, which was dichotomized as class I versus class II-IV, 12 months after surgery. As well, we categorized seizures using the following parameters: type of crisis according to the 2017 ILAE classification, seizure frequency (daily, weekly or monthly) and duration (more or less than one year before surgery) $)^{29}$.

\section{Surgical technique}

Over the years, we have experienced significant technological advancement in resecting tumors in eloquent brain areas. In the first patient from our series, operated on in 2007, the patient presented with a left insular low grade glioma. The tumor was resected through a transsylvian approach based only on microsurgical anatomic landmarks for insular tumors ${ }^{26}$.

From 2008, we had somatosensory and motor evoked potentials ${ }^{30}$ with subcortical electric stimulation become available using the Nicolet Endeavor system (Cardinal Healthcare) to define the medial limits of the resection. We assumed that an electromyographic response in the contralateral body with $7 \mathrm{~mA}$ of subcortical stimulation was the medial limit for safe resection as it is close to the motor tract. For tumors located on or near the rolandic cortex or supplementary motor area we used mapping of the motor cortex with an anesthetized patient.

In 2010, for insular tumors in the dominant hemisphere, we used awake surgery with a transsylvian approach. For insular tumors extending beyond the insula into the frontal and temporal lobes, we used a transcortical approach where silent mapping permitted. From 2010 to 2014, for purely insular tumors located in the dominant hemisphere, we used awake surgery with a transsylvian approach. For insular tumors extending beyond the insula into the frontal and temporal lobes, we used a transcortical approach where silent mapping permitted.

Our parameters of intraoperative cortical and subcortical electrical stimulation were used according to the methodology described by Duffau ${ }^{21,31}$. In patients with insular gliomas undergoing awake surgery, our medial limit for resection was identified primarily through altered speech patterns, such as paraphasia due to electric subcortical stimulation of the inferior fronto-occipital fasciculus. To evaluate the potential involvement of lenticulostriate arteries with the medial aspect of the tumor, we carried out an accurate analysis of the coronal and axial T2- and T1-weighted magnetic resonance (MR) images and considered that tumors that entangled these vessels could not be entirely resected. All patients undergoing awake surgery were submitted to a prior simulation of the surgical procedure.

\section{Volumetric analysis}

Until 2013, we estimated the tumor's volume using the three largest diameters (D1, D2 and D3) of the tumor on T2-weighted MR images. Then, we applied the formula D1 x D2 x D3 / 2. 
Since 2014, we have used the OsiriX (Pixmeo SARL, Geneva, Switzerland) via stored files of MR images in DICOM format (digital imaging and communications in medicine).

The EOR was classified as $<70 \%, 70-90 \%$, $>90 \%$ or gross total resection. The residual tumor volume was subdivided into four categories: < $10 \mathrm{~cm}^{3}, 10-19 \mathrm{~cm}^{3}, 20-29 \mathrm{~cm}^{3}$ and $>30 \mathrm{~cm}^{3}{ }^{10}$. Eight repeated surgical procedures were required due to tumor recurrence. We have not included data from these new surgeries in our statistical analysis.

\section{Statistical analysis}

A descriptive analysis of the data was performed. Categorical variables are shown as absolute (n) and relative (\%) frequencies. Association chi-squared tests and Fisher's exact test were applied to compare all categorical variables. Mann-Whitney tests were applied to compare the distributions in quantitative variables related to the Engel variable.
Survival analysis discriminating the Engel and EOR variables were applied to show the mean, median and the $95 \%$ confidence intervals. Mean time until death was assessed by the log-rank test in each survival analysis. Statistical analysis was performed using SPSS for Windows 18.0 (SPSS Inc., Chicago, IL, USA). A two-tailed p-value $<0.05$ was considered significant.

\section{RESULTS}

\section{Patient population}

The patients' demographic background, preoperative clinical condition, brain mapping type, surgical approach, volumetric analysis of T2-weighted MR images, histological findings, EOR and postoperative status are presented in Table 1.

Table 1. Patients' data and correlation with the Engel seizure classification.

\begin{tabular}{|c|c|c|c|c|c|}
\hline \multirow{3}{*}{ Characteristics } & \multicolumn{4}{|c|}{ Engel } & \multirow{3}{*}{$p$-value* } \\
\hline & \multirow{2}{*}{\multicolumn{2}{|c|}{$\frac{1}{n=11(78.6)}$}} & \multirow{2}{*}{\multicolumn{2}{|c|}{$\begin{array}{c}\text { II. III or IV } \\
n=3(21.4)\end{array}$}} & \\
\hline & & & & & \\
\hline \multicolumn{6}{|l|}{ Sex } \\
\hline Female & $3(60)$ & & $2(40)$ & & 0.505 \\
\hline Male & $8(88.9)$ & & $1(11.1)$ & & \\
\hline Diagnostic (months) & $20.0(40.4)$ & $8.0[1.0 ; 140.0]$ & $15.0(10.8)$ & $18.0[3.0 ; 24.0]$ & 0.456 \\
\hline Age & $35.3(12.4)$ & $35.0[13.0 ; 53.0]$ & $32.7(15.5)$ & $28.0[20.0 ; 50.0]$ & 0.769 \\
\hline Preoperative volume $\left(\mathrm{cm}^{3}\right)$ & $46.1(19.8)$ & $39.0[26.0 ; 98.0]$ & $17.3(7.0)$ & $18.0[10.0 ; 24.0]$ & 0.005 \\
\hline \multicolumn{6}{|l|}{ Seizure classification ${ }^{29}$} \\
\hline Focal aware & $3(100)$ & & $0(0)$ & & 0.140 \\
\hline Focal clonic seizures & $0(0)$ & & $1(100)$ & & \\
\hline Focal impaired awareness & $0(0)$ & & $1(100)$ & & \\
\hline Focal sensory (olfactory) & $2(100)$ & & $0(0)$ & & \\
\hline Focal to bilateral tonic-clonic & $6(85.7)$ & & $1(14.3)$ & & \\
\hline \multicolumn{6}{|l|}{ Seizure frequency } \\
\hline Daily & $3(75)$ & & $1(25)$ & & $>0.999$ \\
\hline Monthly & $2(66.7)$ & & $1(33.3)$ & & \\
\hline Weekly & $6(85.7)$ & & $1(14.3)$ & & \\
\hline \multicolumn{6}{|l|}{ Duration } \\
\hline$<1$ year & $8(88.9)$ & & $1(11.1)$ & & 0.505 \\
\hline$>1$ year & $3(60)$ & & $2(40)$ & & \\
\hline \multicolumn{6}{|l|}{ Preoperative EEG pattern } \\
\hline Epileptic & $6(66.7)$ & & $3(33.3)$ & & 0.607 \\
\hline Normal & $4(100)$ & & $0(0)$ & & \\
\hline Slow & $1(100)$ & & $0(0)$ & & \\
\hline \multicolumn{6}{|l|}{ Location } \\
\hline Insula & $8(100)$ & & $0(0)$ & & 0.053 \\
\hline Motor and/or premotor & $3(60.0)$ & & $2(40.0)$ & & \\
\hline Frontal gyrus & $0(0)$ & & $1(100)$ & & \\
\hline \multicolumn{6}{|l|}{ Tumor enhancement } \\
\hline No & $9(81.8)$ & & $2(18.2)$ & & $>0.999$ \\
\hline Yes & $2(66.7)$ & & $1(33.3)$ & & \\
\hline
\end{tabular}

Continue 


\begin{tabular}{|c|c|c|c|}
\hline \multirow{3}{*}{ Characteristics } & \multicolumn{2}{|c|}{ Engel } & \multirow{3}{*}{$p$-value* } \\
\hline & \multirow{2}{*}{$\begin{array}{c}I \\
n=11(78.6)\end{array}$} & \multirow{2}{*}{$\begin{array}{c}\text { II. III or IV } \\
n=3(21.4)\end{array}$} & \\
\hline & & & \\
\hline \multicolumn{4}{|l|}{ Histological grade } \\
\hline 2 - Diffuse astrocytoma NOS & $8(80)$ & $2(20)$ & 0.665 \\
\hline 3 - Anaplastic astrocytoma NOS & $1(50)$ & $1(50)$ & \\
\hline $\begin{array}{l}4 \text { - Glioblastoma with primitive } \\
\text { neuroectodermal tumor-like components }\end{array}$ & $1(100)$ & $0(0)$ & \\
\hline Ganglioglioma & $1(100)$ & $0(0)$ & \\
\hline \multicolumn{4}{|l|}{ Surgical approach } \\
\hline Transcortical & $2(66.7)$ & 1 (33.3) & 0.449 \\
\hline Transsylvian & $5(100)$ & $0(0)$ & \\
\hline Transsylvian/transcortical & $1(100)$ & $0(0)$ & \\
\hline \multicolumn{4}{|l|}{ Mapping } \\
\hline Motor & $3(75)$ & $1(25)$ & $>0.999$ \\
\hline Motor awake & $3(100)$ & $0(0)$ & \\
\hline Motor/language (awake) & $2(66.7)$ & 1 (33.3) & \\
\hline No & $3(100)$ & $0(0)$ & \\
\hline \multicolumn{4}{|l|}{ EOR } \\
\hline$<70 \%$ & 1 (33.3) & $2(66.7)$ & 0.028 \\
\hline $70-89$ & $0(0)$ & $0(0)$ & \\
\hline$\geq 90 \%$ & $9(100)$ & $0(0)$ & \\
\hline Supratotal & $1(50)$ & $1(50)$ & \\
\hline \multicolumn{4}{|l|}{ Immediate postoperative } \\
\hline Aphasic and hemiplegic & $1(100)$ & $0(0)$ & 0.275 \\
\hline Hemiparesis & $2(66.7)$ & 1 (33.3) & \\
\hline No & $8(88.9)$ & $1(11.1)$ & \\
\hline Worse aphasia & $0(0)$ & $1(100)$ & \\
\hline \multicolumn{4}{|l|}{ Follow-up (6 months) } \\
\hline $\begin{array}{l}\text { Motor aphasia and hemiparetic / } \\
\text { Karnofsky Performance Status } 60\end{array}$ & $1(100)$ & $0(0)$ & 0.392 \\
\hline No / Karnofsky Performance Status 100 & $10(83.3)$ & $2(16.7)$ & \\
\hline No Karnofsky Performance Status 70 & $0(0)$ & $1(100)$ & \\
\hline \multicolumn{4}{|l|}{ Postoperative volume } \\
\hline Partial resection & 1 (33.3) & $2(66.7)$ & 0.030 \\
\hline Supratotal resection & $1(50)$ & $1(50)$ & \\
\hline Total resection & $9(100)$ & $0(0)$ & \\
\hline \multicolumn{4}{|l|}{ Sanai ${ }^{12}$} \\
\hline “Giant” & $2(100)$ & $0(0)$ & \\
\hline Zone 1 & $4(100)$ & $0(0)$ & \\
\hline Zone $1+4$ & $1(100)$ & $0(0)$ & \\
\hline Zone $3+4$ & $1(100)$ & $0(0)$ & \\
\hline \multicolumn{4}{|l|}{ Yasargil ${ }^{23}$} \\
\hline $3 A$ & $1(100)$ & $0(0)$ & \\
\hline $3 B$ & $3(100)$ & $0(0)$ & \\
\hline $5 \mathrm{~A}$ & $3(100)$ & $0(0)$ & \\
\hline $5 B$ & $1(100)$ & $0(0)$ & \\
\hline \multicolumn{4}{|l|}{ Lenticulostriate arteries involvement } \\
\hline No & $7(100)$ & $0(0)$ & \\
\hline Yes & $1(100)$ & $0(0)$ & \\
\hline \multicolumn{4}{|l|}{ Additional treatment } \\
\hline Chemotherapy & $0(0)$ & $1(100)$ & 0.392 \\
\hline Chemotherapy plus radiotherapy & $2(66.7)$ & 1 (33.3) & \\
\hline No & $4(80)$ & $1(20)$ & \\
\hline $\begin{array}{l}\text { Second and third surgery procedure / } \\
\text { chemotherapy plus radiotherapy }\end{array}$ & $4(100)$ & $0(0)$ & \\
\hline Second surgery procedure - radiotherapy & $1(100)$ & $0(0)$ & \\
\hline \multicolumn{4}{|l|}{ Status } \\
\hline Alive & $6(75)$ & $2(25)$ & $>0.999$ \\
\hline Deaths & $5(83.3)$ & $1(16.7)$ & \\
\hline
\end{tabular}


This study included nine male and five female patients, and seizure was the primary symptom among them. Their period of refractory epilepsy ranged from 2-15 months. For statistical analysis, we categorized the refractory period into less than, and more than, one year. Five (35.7\%) patients had refractory seizures for more than one year. Of these, four were referred after brain biopsy for oncological treatment.

Seven (50\%) patients had insular gliomas, one of whom had a histological diagnosis of glioblastoma with primitive neuroectodermal tumor-like components. One (7.1\%) patient had an insular ganglioglioma. The 6 (35.7\%) remaining patients had low grade gliomas located in the supplementary motor area $(n=5 ; 28-35.7 \%)$ and Broca's area $(n=1$; $7.1 \%$ ). Tumor volume ranged from $13 \mathrm{~cm}^{3}$ to $53 \mathrm{~cm}^{3}$.

\section{Surgical technique and postoperative course}

Motor mapping was used in all patients with tumors located in the rolandic cortex or supplementary motor area. In three of these, the patients were submitted to awake craniotomies, and the other two were anesthetized. For the anesthetized patients, the tumors were completely resected, and patients did not show any motor or speech dysfunction at the six-month follow-up. For the three patients who underwent awake surgery, gross total resection was achieved in two of them and partial resection in the last one. At six months, there was no neurological dysfunction in any of these patients.

Regarding surgery on insular gliomas presenting with drug-resistant epilepsy, only our first patient developed permanent mild aphasia and hemiparesis, probably related to the disruption of the inferior fronto-occipital fasciculus and arcuate fasciculus. There was no neurophysiologic intraoperative monitoring available at that time; however, the high frequency of seizures justified the procedure. All other patients with insular gliomas had no permanent deficit. Apart from one patient (Figure 1), whose tumor harbored lenticulostriate arteries in the medial portion, the EOR was $>90 \%$ in all patients (Figure 2).
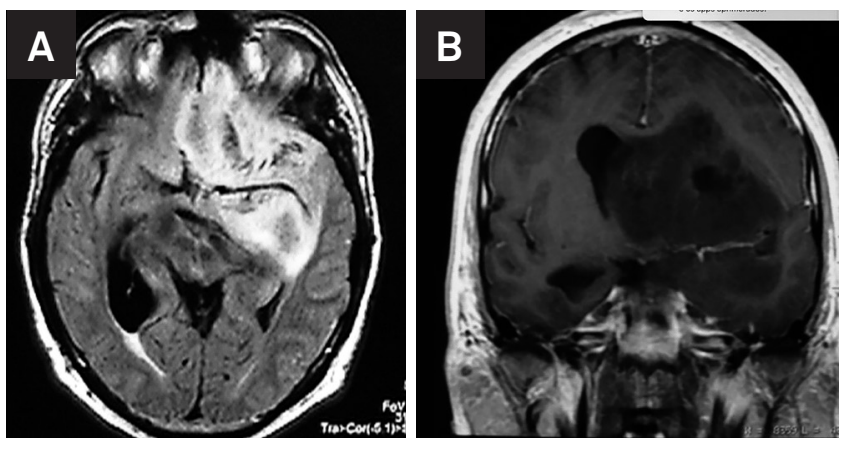

Figure 1. (A) Axial view T2-weighted brain MRI showing a hyperintense lesion in the left mesial temporal lobe involving the left middle cerebral artery. (B) Coronal view of T1-weighted brain MRI showing a hypointense lesion located in the origin of the lenticulostriate arteries. The involvement of the lenticulostriate arteries should be considered as an important limitation for gross total resection.
The surgical approach to insular gliomas did not influence the final result regarding the EOR and neurological preservation. However, the transsylvian corridor approach to middle cerebral artery manipulation caused intense headache, discomfort and prolonged brain mapping. Therefore, we preferred a transcortical approach with subpial resection.

The patient with a tumor in Broca's area was a native Portuguese speaker, but also fluent in English and Spanish. During intraoperative subcortical stimulation of the inferior frontal gyrus he presented with the language switching phenomenon and started answering questions in English ${ }^{22,32}$. Thus, we performed only partial resection of the lesion.

For the insular gliomas, we used the Yaşargil ${ }^{23}$ and BergerSanai classifications ${ }^{12}$. However, there was no statistical correlation between these classification systems and the EOR (Table 2). The glioma of the insula on which partial resection was performed due to the involvement of lenticulostriate arteries was classified as Yaşargil 5B, or giant tumor in the BergerSanai classifications. Neither of these classification systems consider the involvement of these arteries, an important aspect to be considered for the degree of resection in insular gliomas. When we compared these two classification systems, we noted that all giant tumors were classified as $5 \mathrm{~A}$ in the Berger-Sanai Classification or 5B tumors in the Yaşargil Classification.

Cortical and subcortical mapping was performed in 13 patients. The first patient of the series was operated on without stimulation, as this was not available. For the other two patients (a right insular low grade glioma and a left insular ganglioglioma), neurophysiological monitoring was not considered necessary due to the relatively low risk for development of permanent postoperative neurological deficits.

Gross total resection (EOR > 90\%) was achieved in $11(78.5 \%)$ patients.

\section{Predictive factors of postoperative seizure}

When analyzing the effect of surgery on seizure control in our drug-resistant epilepsy patients, we achieved good outcomes in seizure control. For comparison analysis, we divided postoperative seizures into two groups, either Engel I or Engel II, III and IV (Table 1). In the one-year follow up, $78.6 \%$ of patients presented with good seizure control and, of the remaining $21.4 \%$, one was classified as Engel II and two as Engel III. The patients classified as Engel I and II maintained the same anti-epileptic drug doses after surgery. The patient who still had drug-resistant epilepsy even after surgery did not reduce their frequency of seizures after new anti-epileptic drug regimens.

In patients who had tumor recurrence, all occurred at least one year after surgery and the predominant symptom was an increase in seizure frequency. Even with no statistical relevance, the survival rate was higher in the Engel II, III and IV group. The survival analysis showed a mean of 103 months in the Engel I group and 140.4 months in the Engel II, III and IV group ( $\mathrm{p}=0.295)$ (Table 3$)$. 

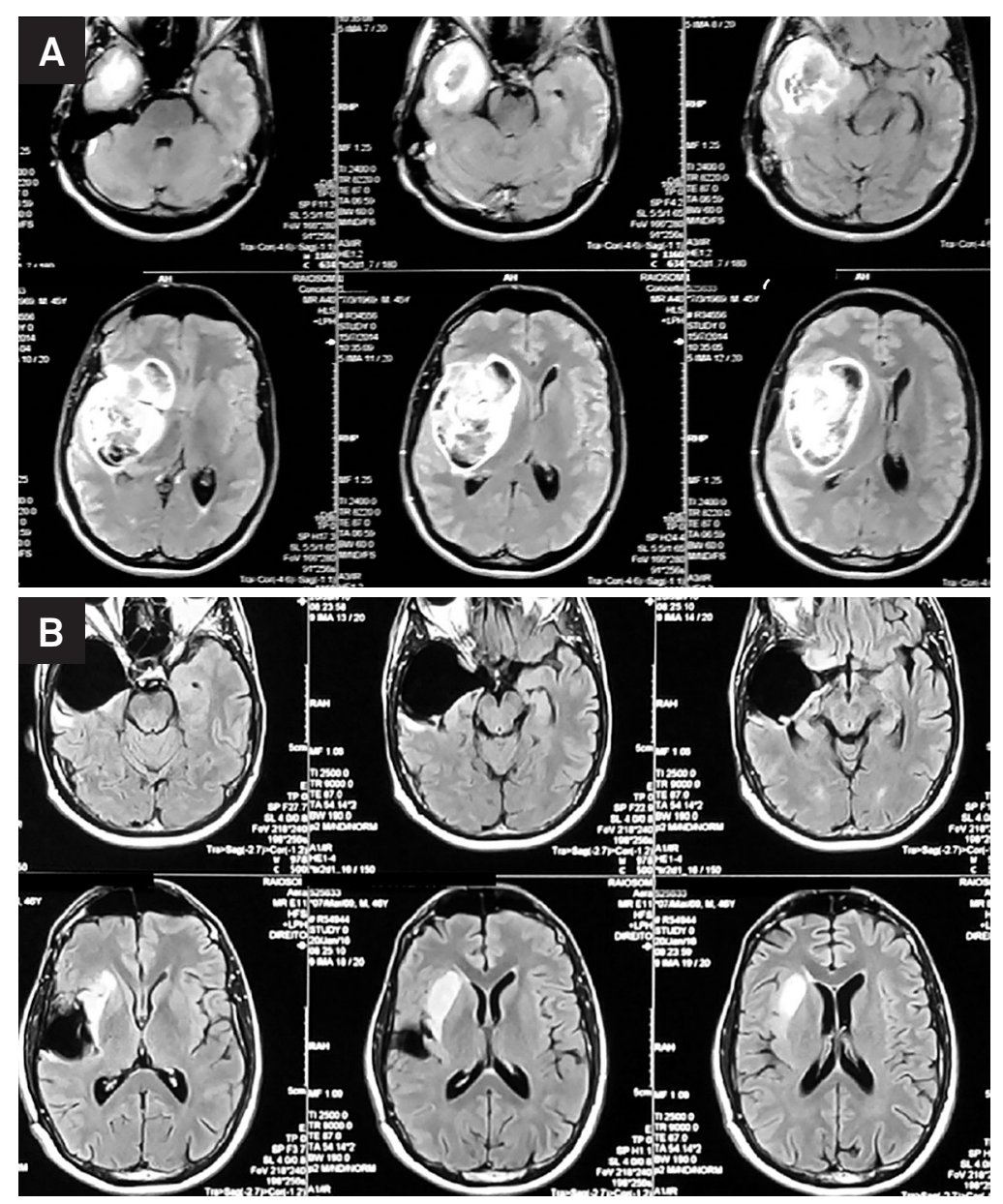

Figure 2. (A) Preoperative brain MRI / (B) Postoperative brain MRI showing a residual lesion based on the microsurgical anatomy, direct visualization of the lenticulostriate arteries and motor subcortical stimulation. The patient had no deficits in the follow-up and good control of seizures.

Table 2. Relationship between extent of resection and insular glioma's classification.

\begin{tabular}{lccc}
\hline \multirow{2}{*}{ Variable } & \multicolumn{2}{c}{ EOR } & p-value \\
\cline { 2 - 3 } & $\langle 70 \%$ & $>90 \%$ & \\
Sanai19 & & & \\
Giant & $1(50)$ & $1(50)$ & 0.503 \\
zone 1 & $0(0)$ & $4(100)$ & \\
zone 1+4 & $0(0)$ & $1(100)$ & \\
zone 3+4 & $0(0)$ & $1(100)$ & \\
Yasargil ${ }^{37}$ & & & \\
3A & $0(0)$ & $1(100)$ & 0.251 \\
3B & $0(0)$ & $3(100)$ & \\
5A & $0(0)$ & $3(100)$ & \\
5B & $1(100)$ & $0(0)$ & \\
Lenticulostriate arteries encasement & & \\
No & $0(0)$ & $7(100)$ & 0.125 \\
Yes & $1(100)$ & $0(0)$ & \\
\hline
\end{tabular}

EOR: extent of resection.

Regarding insular gliomas, there was no correlation between the type of classification and the EOR. However, the involvement of lenticulostriate arteries by the tumor is an important limiting factor to achieving gross total resection ${ }^{7,16}$.

\section{DISCUSSION}

Drug-resistant epilepsy prevalence varies between 15.6\% and $37 \%{ }^{33}$ among people with epilepsy. Those patients may have structural abnormalities that explain the frequency of this crisis without complete response to the pharmacological treatment.

\section{Eloquent areas and intraoperative brain mapping}

Low grade gliomas are commonly located in eloquent areas of the brain ${ }^{6}$ and it has already been demonstrated that intraoperative functional mapping may improve long-term survival in those with low grade gliomas located in eloquent brain regions. Chang et al. ${ }^{34}$ conducted a retrospective study with a long-term follow-up of 281 adult patients with hemispheric infiltrative low grade gliomas who underwent surgical treatment. More than half of the patients harbored tumors that directly involved the presumed eloquent areas. However, they also defined "false eloquent areas" adjacent to eloquent brain, based on the intraoperative monitoring. Therefore, those standard eloquent areas postulated in the basic anatomy may not represent a functionally relevant region, suggesting that mapping can drastically change the long-term prognosis for these patients 
Table 3. Relationship between extent of resection and Engel Class.

\begin{tabular}{lcccc} 
Variable & No Events & Censored & \multicolumn{2}{c}{ Survival analysis } \\
Engel & & & mean $[\mathrm{Cl} 95 \%]$ & median $[\mathrm{Cl} 95 \%]$ \\
I & 11 & 6 & $103.0[68.9 ; 137.1]$ & $92.8[26.7 ; 158.8]$ \\
II/III & 3 & 2 & $140.4[140.4 ; 140.4]$ & $140.4[-;-]$ \\
EOR & 2 & 1 & $116.6[69.9 ; 163.3]$ & $92.8[-;-]$ \\
$<70$ & 0 & 0 & - & - \\
$70-89$ & 4 & 5 & 105.2 & $21.2[60.4 ; 143.5]$ \\
$\geq 90$ & 0 & 2 & 64 & $64[-;-]$ \\
Supratotal & 14 & 8 & $113.4[83.4 ; 143.3]$ & $102.0[43.3 ; 160.6]$ \\
Global & & & 0.859 \\
\hline
\end{tabular}

EOR: extent of resection; Kaplan-Meier Analysis - Log Rank Test.

In our series, three patients had partial resection surgery for tumors located in Broca's area, in the left insular glioma with lenticulostriate arteries involvement and in the primary motor cortex. The patients were discharged without new neurological deficits; however, the oncological gross total resection could not always be achieved. Expertise in microsurgical anatomy, in addition to the brain mapping technique, is the gold standard treatment for eloquent area gliomas. It provides neurological preservation with maximal surgical resection, as subtotal resection is associated with the recurrence of gliomas of a higher grade ${ }^{35}$.

One interesting finding involved a patient with a tumor in the inferior frontal gyrus ${ }^{32}$. Cortical and subcortical language organization in bilingual patients with epilepsy, or those who developed language switching brain tumors, has been studied previously $y^{22,32,36}$. All the authors identified language-common areas and language-specific areas by stimulating cortical structures, while Bello et al..$^{22}$ also identified language-specific white matter fiber tracts by stimulating subcortical structures. In our case, the patient switched language from their native Portuguese to English during stimulation of the left inferior frontal gyrus.

The activation of different languages is usually found to occur within the same region ${ }^{36}$, or dependent on the intensity of cortical stimulation ${ }^{37}$. It has been observed that lexical processing is related to declarative memory and is similar for both native and second languages, while sentence processing depends on procedural memory, which can differ between native and second languages ${ }^{38}$.

\section{Predictive factors of seizure control}

This study selected patients with tumors in eloquent areas who also had refractory epilepsy, and studied the surgical impact on the Engel Class. Although the correlation of epilepsy with glioma surgery has been studied before, only one previous study ${ }^{4}$ correlated refractory epilepsy with gliomas in eloquent areas. Studying this subgroup of patients is important because tumor resection is avoided in eloquent areas considering the high risk of sequelae and their negative impact on quality of life. However, this consideration must be balanced against the lowered quality of life of this population due to refractory epilepsy9. In these patients, the need for surgery, regardless of the neuro-oncological premise, is mandatory. We have shown in our patients that the preoperative tumor volume and degree of resection were determinants for seizure control. In accordance with our findings, Ius et al. ${ }^{4}$ and Chang et al. ${ }^{39}$ demonstrated a statistically significant correlation between the EOR and seizure control.

Although we did not find a statistically significant correlation between early surgery and seizure control, we believe this was due to the small number of patients in our series.

Ius et $\mathrm{al}^{4}$. correlated monthly seizures and preoperative normal EEGs with better postoperative seizure control. They also measured the preoperative volumetric difference on T2- and T1-weighted MR images and their volumetric of the EOR and this T2- and T1-weighted difference. They found a higher correlation using this method than using volumetric analysis on T2- or T1-weighted images. They concluded that a less invasive tumor offered a better chance of greater EOR and, by extension, a better chance for postoperative seizure control. ${ }^{4}$ In this sense, the invasive tumor determined in T2-weighted images was considered by these authors as a new predictive index. This understanding favors resection based on preoperative T2-weighted image ${ }^{20}$. This is the conceptual basis we have used in recent years regarding patients undergoing awake surgery in which the border of tumor resection is determined by function instead of anatomy.

We did not use intraoperative electrocorticography in our patients but performed tumor resection based on anatomy brain mapping. The electrocorticography would not have altered the degree of resection because a functional area would not have been resected anyway. In addition, we wanted to avoid intraoperative seizures after stimulation. In our hospital, we reserved electrocorticography for extra-temporal refractory epilepsy due to cortical dysplasia.

\section{Study limitations}

The limited sample size prevented COX regression analysis in evaluating the predictors of the Engel outcome in our series. We also did not use molecular biology analysis to 
identify gliomas or correlate any specific marker that may have predicted the prognosis of epileptic seizures. Performing a randomized prospective study on this group of patients with the objective of searching for credible evidence would be restricted by ethical considerations as the technique of brain mapping is already well-established and the surgical technique should not be modified to create a unique study group. On the other hand, if we compare the first few in a series of patients operated on without brain mapping by one neurosurgeon with the more recent patients in the series operated on, and brain mapped, by the same surgeon, we would be failing to account for any learning curve variables that would be expected to impact the more recent patients in a positive way.

In conclusion, there is a relevant correlation between EOR and the Engel scale. An EOR $<70$ is associated with Engel II, III, IV and an EOR > 90 is associated with better seizure control (Engel I). Due to oncological factors, patients with refractory epilepsy should be operated on earlier than patients without structural lesions.

\section{References}

1. Kwan P, Arzimanoglou A, Berg AT, Brodie MJ, Allen Hauser W, Mathern G, et al. Definition of drug resistant epilepsy: consensus proposal by the ad hoc Task Force of the ILAE Commission on Therapeutic Strategies. Epilepsia. 2010 Jun;51(6):1069-77. https://doi.org/10.1111/j.1528-1167.2009.02397.x

2. Engel $J \mathrm{~J}$ r. Surgical treatment for epilepsy: too little, too late? JAMA. 2008 Dec;300(21):2548-50. https://doi.org/10.1001/jama.2008.756

3. Helmstaedter C, Kockelmann E. Cognitive outcomes in patients with chronic temporal lobe epilepsy. Epilepsia. 2006;47(s2 Suppl 2):96-8. https://doi.org/10.1111/j.1528-1167.2006.00702.x

4. Ius T, Pauletto G, Isola M, Gregoraci G, Budai R, Lettieri C, et al. Surgery for insular low-grade glioma: predictors of postoperative seizure outcome. J Neurosurg. 2014 Jan;120(1):12-23. https://doi.org/10.3171/2013.9.JNS13728

5. Smits A, Duffau H. Seizures and the natural history of World Health Organization Grade II gliomas: a review. Neurosurgery. 2011 May;68(5):1326-33. https://doi.org/10.1227/NEU.0b013e31820c3419

6. Duffau H, Capelle L. Preferential brain locations of low-grade gliomas. Cancer. 2004 Jun;100(12):2622-6. https://doi.org/10.1002/cncr.20297

7. Duffau H. A personal consecutive series of surgically treated 51 cases of insular WHO Grade II glioma: advances and limitations. J Neurosurg. 2009 Apr;110(4):696-708. https://doi.org/10.3171/2008.8.JNS08741

8. Ghareeb F, Duffau H. Intractable epilepsy in paralimbic Word Health Organization Grade II gliomas: should the hippocampus be resected when not invaded by the tumor? J Neurosurg. 2012 Jun;116(6):1226-34. https://doi.org/10.3171/2012.1.JNS112120

9. Klein M, Engelberts NH, van der Ploeg HM, Kasteleijn-Nolst Trenité DG, Aaronson NK, Taphoorn MJ, et al. Epilepsy in low-grade gliomas: the impact on cognitive function and quality of life. Ann Neurol. 2003 Oct;54(4):514-20. https://doi.org/10.1002/ana.10712

10. Ius T, Isola M, Budai R, Pauletto G, Tomasino B, Fadiga L, et al. Low-grade glioma surgery in eloquent areas: volumetric analysis of extent of resection and its impact on overall survival. A singleinstitution experience in 190 patients: clinical article. J Neurosurg. 2012 Dec;117(6):1039-52. https://doi.org/10.3171/2012.8.JNS12393

11. Sanai N, Berger MS. Glioma extent of resection and its impact on patient outcome. Neurosurgery. 2008 Apr;62(4):753-64. https://doi.org/10.1227/01.neu.0000318159.21731.cf

12. Sanai N, Polley MY, Berger MS. Insular glioma resection: assessment of patient morbidity, survival, and tumor progression. J Neurosurg. 2010 Jan;112(1):1-9. https://doi.org/10.3171/2009.6.JNS0952-

13. van Breemen MS, Wilms EB, Vecht CJ. Epilepsy in patients with brain tumours: epidemiology, mechanisms, and management. Lancet Neurol. 2007 May;6(5):421-30. https://doi.org/10.1016/S1474-4422(07)70103-5
14. Berger MS, Deliganis AV, Dobbins J, Keles GE. The effect of extent of resection on recurrence in patients with low grade cerebral hemisphere gliomas. Cancer. 1994 Sep;74(6):1784-91. https://doi.org/10.1002/1097-0142(19940915)74:6<1784::AIDCNCR2820740622>3.0.CO;2-D

15. Yașargil MG. From the microsurgical laboratory to the operating theatre. Acta Neurochir (Wien). 2005 May;147(5):465-8. https://doi.org/10.1007/s00701-005-0519-1 -

16. Türe $U$, Yașargil MG, Friedman AH, Al-Mefty $O$. Fiber dissection technique: lateral aspect of the brain. Neurosurgery. 2000 Aug;47(2):417-26. https://doi.org/10.1097/00006123-200008000-00028

17. Rhoton AL Jr. The cerebrum. Anatomy. Neurosurgery. 2007 Jul;61(1 Suppl):37-118. https://doi.org/10.1227/01.NEU.0000255490.88321.CE

18. Ribas GC, Yasuda A, Ribas EC, Nishikuni K, Rodrigues AJ Jr. Surgical anatomy of microneurosurgical sulcal key points. Neurosurgery. 2006 Oct;59(4 Suppl 2):ONS177-210.-

19. Duffau H, Peggy Gatignol ST, Mandonnet E, Capelle L, Taillandier L. Intraoperative subcortical stimulation mapping of language pathways in a consecutive series of 115 patients with Grade II glioma in the left dominant hemisphere. J Neurosurg. 2008 Sep;109(3):461-71. https://doi.org/10.3171/JNS/2008/109/9/0461

20. Duffau H. Surgery of low-grade gliomas: towards a 'functional neurooncology'. Curr Opin Oncol. 2009 Nov;21(6):543-9. https://doi.org/10.1097/CC0.0b013e3283305996

21. Duffau H. Lessons from brain mapping in surgery for low-grade glioma: insights into associations between tumour and brain plasticity. Lancet Neurol. 2005 Aug;4(8):476-86. https://doi.org/10.1016/S1474-4422(05)70140-X

22. Bello L, Acerbi F, Giussani C, Baratta P, Taccone P, Songa V. Intraoperative language localization in multilingual patients with gliomas. Neurosurgery. 2006 Jul;59(1):115-25. https://doi.org/10.1227/01.NEU.0000219241.92246.FB

23. Yașargil MG, von Ammon K, Cavazos E, Doczi T, Reeves JD, Roth P. Tumours of the limbic and paralimbic systems. Acta Neurochir (Wien). 1992;118(1-2):40-52. https://doi.org/10.1007/BF01400725

24. Louis DN, Perry A, Reifenberger G, Deimling A, Figarella-Branger D, Cavenee WK, et al. The 2016 World Health Organization Classification of Tumors of the Central Nervous System: a summary. Acta Neuropathol. 2016 Jun;131(6):803-20. https://doi.org/10.1007/s00401-016-1545-1 -

25. Espírito-Santo H, Pires CF, Garcia IQ, Daniel F, Silva AG, Fazio RL. Preliminary validation of the Portuguese Edinburgh Handedness Inventory in an adult sample. Appl Neuropsychol Adult. 2017 May-Jun;24(3):275-87. https://doi.org/10.1080/23279095.2017.1290636 
26. Yașargil GM, Krisht AF, Türe U, Al-Mefty O, Yașargil D. Microsurgery of insular gliomas: part IV: surgical treatment and outcome. Contemp Neurosurg. 2002;24(14):1-8. https://doi.org/10.1097/00029679-200207150-00001

27. Mansur LL, Radanovic M, Taquemori L, Greco L, Araújo GC. A study of the abilities in oral language comprehension of the Boston Diagnostic Aphasia Examination Portuguese version: a reference guide for the Brazilian population. Braz J Med Biol Res. 2005 Feb;38(2):277-92. https://doi.org/10.1590/S0100-879X2005000200017

28. Karnofsky DA, Burchenal JH. The clinical evaluation of chemotherapeutic agentes in Cancer. In: MacLeod CM. Evaluation of chemotherapeutic agentes. New York: Columbia University Press; 1949. p. 191-205.

29. Fisher RS, Cross JH, French JA, Higurashi N, Hirsch E, Jansen FE, et al. Operational classification of seizure types by the International League Against Epilepsy: Position Paper of the ILAE Commission for Classification and Terminology. Epilepsia. 2017 Apr;58(4):522-30. https://doi.org/10.1111/epi.13670

30. Neuloh $\mathrm{G}$, Pechstein U, Schramm J. Motor tract monitoring during insular glioma surgery. J Neurosurg. 2007 Apr;106(4):582-92. https://doi.org/10.3171/jns.2007.106.4.582

31. Duffau H. Resecting diffuse low-grade gliomas to the boundaries of brain functions: a new concept in surgical neuro-oncology. $J$ Neurosurg Sci. 2015 Dec;59(4):361-71.

32. Moritz-Gasser S, Duffau H. Evidence of a largescale network underlying language switching: a brain stimulation study. J Neurosurg. 2009 Oct;111(4):729-32. https://doi.org/10.3171/2009.4.JNS081587
33. Picot MC, Baldy-Moulinier M, Daurès JP, Dujols P, Crespel A. The prevalence of epilepsy and pharmacoresistant epilepsy in adults: a population-based study in a Western European country. Epilepsia. $2008 \mathrm{Jul} ; 49(7): 1230-8$. https://doi.org/10.1111/j.1528-1167.2008.01579.x

34. Chang EF, Clark A, Smith JS, Polley MY, Chang SM, Barbaro $\mathrm{NM}$, et al. Functional mapping-guided resection of low-grade gliomas in eloquent areas of the brain: improvement of long-term survival. Clinical article.J Neurosurg. 2011 Mar;114(3):566-73. https://doi.org/10.3171/2010.6.JNS091246

35. Talos IF, Zou KH, Ohno-Machado L, Bhagwat JG, Kikinis R, Black PM, et al. Supratentorial low-grade glioma resectability: statistical predictive analysis based on anatomic MR features and tumor characteristics. Radiology. 2006 May;239(2):506-13. https://doi.org/10.1148/radiol.2392050661

36. Roux FE, Trémoulet M. Organization of language areas in bilingual patients: a cortical stimulation study. J Neurosurg. 2002 Oct;97(4):857-64. https://doi.org/10.3171/jns.2002.97.4.0857

37. Pouratian N, Cannestra AF, Bookheimer SY, Martin NA, Toga AW. Variability of intraoperative electrocortical stimulation mapping parameters across and within individuals. J Neurosurg. 2004 Sep;101(3):458-66. https://doi.org/10.3171/jns.2004.101.3.0458

38. Kim KH, Relkin NR, Lee KM, Hirsch J. Distinct cortical areas associated with native and second languages. Nature. 1997 Jul;388(6638):171-4. https://doi.org/10.1038/40623

39. Chang EF, Potts MB, Keles GE, Lamborn KR, Chang SM, Barbaro NM, et al. Seizure characteristics and control following resection in 332 patients with low-grade gliomas. $J$ Neurosurg. 2008 Feb;108(2):227-35. https://doi.org/10.3171/JNS/2008/108/2/0227 